\title{
Comprehensive Teacher Induction: Meeting The Dual Needs Of Principals And New Teachers In Rural Schools
}

Craig D. Kono, Northern State University, USA

\begin{abstract}
This research project is the third in a series of research projects conducted for the purpose of assisting rural school principals create comprehensive first-year teacher induction programs. This project promotes the use of comprehensive teacher induction programs that meet both the needs of school principals, but also the social, personal, and family needs of new teachers starting their education careers in rural schools in South Dakota. The data was collected from previous teacher skills and school traits studies involving school principals and first-year teachers from across South Dakota. This report was created through the Northern State University Teacher Induction Program, a follow-up support and data collection program intended for new teachers entering education upon graduation from Northern State University in Aberdeen, South Dakota. The data collected documents trends and issues and is reported annually to Northern State University School of Education.
\end{abstract}

Keywords: Teacher Induction; School Traits; Northern State University; New Teachers; First-Year Teachers

\section{INTRODUCTION}

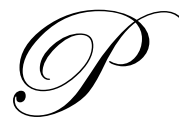

rincipals in rural schools face yearly teacher shortage dilemmas when trying to recruit and retain new teachers to fill staff vacancies. New teachers also face a myriad of issues in their first years in education, including difficult work assignments, unclear expectations, inadequate resources, isolation, role conflicts and reality shock (Gordon \& Maxey, 2000). Understanding the complex needs of school administrators and new teachers may lie in the development of comprehensive teacher induction programs focused on new teacher training and support, both in and out of the classroom. Successful teacher induction programs should teach diverse and unique methods of helping new teachers adjust to the teaching profession in their new schools, but they can also help address the social and personal needs of new teachers starting their careers in small towns and rural communities.

National data reveal that when a teacher leaves a school district it costs an average of nearly $\$ 11,000$ to replace them due to the lost investment. At least 14 percent of K-12 teachers may either switch schools or leave the profession yearly costing districts nationwide nearly $\$ 5.8$ billion. Schools with low income families in difficult settings experience the highest new teacher attrition rates (Graziano, 2005). Data support the notion that teacher induction programs do help to decrease the number of teachers leaving education. Table 1 on the following page illustrates the attrition rate between teachers who have not participated in teacher induction programs and those who have participated. The findings revealed a 17.6 percent attrition rate for teacher induction non-participants, compared to 11.9 percent attrition rate for participants. Similarly, those schools with a mentorship program for first year teachers experienced an attrition rate of 18.6 percent for non-participants, and 11.8 percent attrition rate for participants (Ingersoll \& Smith, 2003). Richard Ingersoll, a professor at the University of Pennsylvania, cited in Graziano (2005), concludes that new teachers receiving no first year training programs are twice as likely to leave the teaching profession as those who receive more substantial support. "When new teachers are not allowed time for professional development, many end up going without, and eventually they just go" (Graziano, 2005). 
Table 1

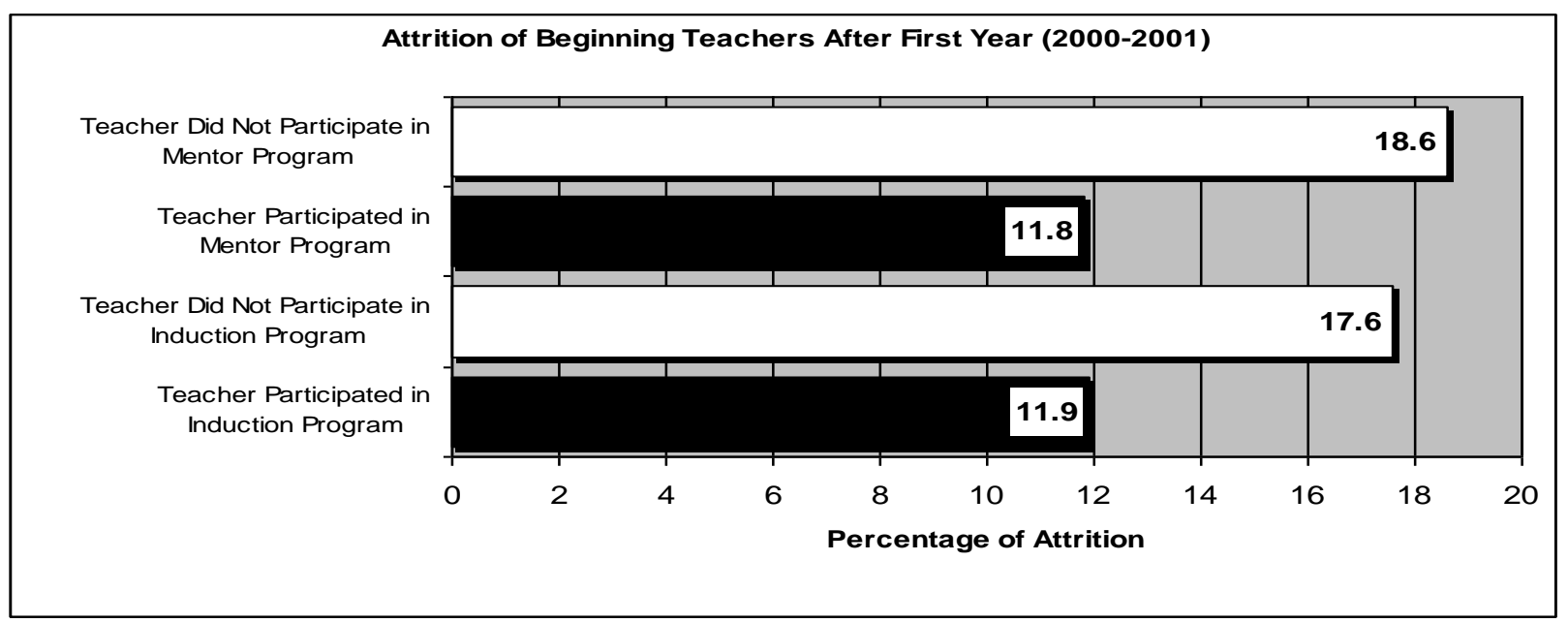

Source: National Center for Education Statistics

Every year schools throughout the United States hire nearly 200,000 teachers, and by the end of the first year, nearly 22,000 teachers have left the education profession. Thirty-three percent of teachers in the United States will leave teaching after three years, and 46 percent of new teachers will leave teaching after five years (Ingersoll, 2005). Additionally, 37 percent of the people in the teaching profession are over 50 years of age and considering retirement. These figures compare similarly to South Dakota data that indicate nearly 60 percent of teachers are expected to retire from South Dakota's rural schools in the next 25 years (Associated School Boards of South Dakota, 2006).

When we combine the data above with a growing teacher shortage in small towns, and the fact that fewer and fewer new teachers are willing to move into remote rural towns tucked far away from population centers, small town schools are facing a crisis situation. During this time of educational uncertainty in rural states like South Dakota it has become increasingly important for rural schools to consider incorporating comprehensive teacher induction programs that support the dual needs of school principals and young teachers. As Toner states, "It is a familiar story across rural stretches of the Great Plains, where the state of the local schools often serves as a barometer for the health of the community." Maintaining a strong instructional staff is an essential element of the health and vitality of the school and the community itself.

\section{DATA COLLECTION}

This study was created and conducted by educators involved in the Teacher Induction Program at Northern State University, a small liberal arts university in rural northeastern South Dakota with a 108 year history of preparing students to become classroom teachers, counselors, and school principals. The mission of the NSU Teacher Induction Program is to serve as a follow-up support program for first-year teachers from NSU, and to help them better understand issues they may face in schools as they start their teaching careers.

An initial traits and needs study was first conducted in 2009 by asking forty-five South Dakota school principals to rate and rank school and classroom traits and skills they considered most important for future teachers. During the spring semester of 2010, sixty-two first-year and aspiring teachers from Northern State University were asked to rate and rank a set of sixty classroom and community traits they considered important when searching for a school in which to teach for the first time. Finally, the needs of principals and teachers were compared and combined with other national teacher induction projects and assessment models promoting successful school performance. 


\section{DISCUSSION}

Evidence collected supports the notion that teacher induction programs help first-year teachers succeed in school, however South Dakota school principals need to consider taking them a step further. Induction programs can help first-year teachers establish effective classroom routines, management procedures, and sound instructional strategies, but they should also be created with the thought of increasing retention rates by meeting the social and personal needs of new teachers who may have strong misgivings about moving into smaller communities even moderately far from larger towns.

When considering their first classroom teaching opportunity, first-year teachers graduating from Northern State University in the spring semester of 2010 contemplated starting their education careers in small towns and country schools. One first-year teacher decided to move into a small town, but soon discovered there was no grocery store available to purchase simple medicinal items for a common cold. School district reorganization and consolidation are other threats that hinder small districts in their recruitment efforts. One new teacher stated, "I wanted a new school with a bright future, I did not want one that would be closing down in the next year or two." Other new teachers were more fearful of feelings of isolation and loneliness. One student stated, "Feelings of isolation may stunt my growth as a teacher and lead me to pursue a different field of study."

In a 2010 first-year teacher needs study, forty-four percent of Northern State University School of Education graduates said they would choose to stay in the upper Midwest, but nearly one-third of new teachers did not want to teach in South Dakota, and 79\% of new teachers would not choose school locations and communities located in isolated, rural communities far from population centers. This information supports a clear concern for rural school administrators, and the increasing need for schools to show support for new teachers in small towns. It is essential that school administrators consider developing induction programs that do more than teach classroom skills, but also marry the professional needs of schools with the personal needs of new teachers and help them become socialized in rural communities that are often very tight knit and hard to get to know.

The teacher needs study also asked sixty-two first-year teachers to rate and rank a common set of school and community traits that interested them most. Ninety-five percent of new teachers from Northern State University believed a welcoming friendly attitude was either preferred or highly preferred, while 88.4 percent of new and firstyear teachers considered healthcare needs preferred or highly preferred. Other school location and community traits that were preferred or highly preferred were nearby shopping and groceries opportunities (83.7\%), a short commute to school (81.4\%), and a community that was good for their families (76.8).

First Year Teacher Needs:

$\begin{array}{ll}\text { - } & \text { Welcoming Attitude } \\ \text { - } & \text { Safe Environment } \\ \text { - } & \text { Comfortable Housing } \\ \text { - } & \text { Short Commute to School } \\ \text { - } & \text { Shopping and Groceries Nearby } \\ \text { - } & \text { Malthare Nearby } \\ \text { - } & \text { Good Community Resources } \\ \text { - } & \text { Opportunities for Career Longevity }\end{array}$

In 2009, forty-five South Dakota school principals surveyed were seeking evidence of a baseline set of classroom needs and skills from the first-year teachers. Nearly $100 \%$ of principals surveyed wanted new teachers that had a passion for education, a strong desire to work with students, and high quality interpersonal skills to connect with both other professionals in their schools and parents in the local community. South Dakota school administrators also wanted first-year teachers with a genuine personality, a passion for teaching students, and positive, professional attitudes. South Dakota principals needed teachers who possessed a strong work ethic and good planning skills. 
School Principal Needs:

$\begin{array}{ll}\text { - } & \text { Positive Attitude } \\ \text { - } & \text { Interpersonal Skills } \\ \text { - } & \text { Trustworthiness } \\ \text { - } & \text { Professiasm } \\ \text { - } & \text { Communication Skills } \\ \text { - } & \text { Commitment to Education } \\ \text { - } & \text { Purposeful Lessons } \\ \text { - } & \text { Classroom Management Skills } \\ \text { - } & \text { Planning and Preparation Skills }\end{array}$

One answer to understanding the problems school administrators face while attempting to find and retain new teachers rests in the development of comprehensive teacher induction programs focused on meeting both school needs of principals and the social and personal needs of new teachers. School administrators can create meaningful teacher induction programs that incorporate diverse and unique features to help new teachers adjust to their new rural schools. Induction programs can continue for several years beyond the first year of teaching and incorporate differentiated methods of helping new teachers adjust to their new schools and communities.

Elements of Comprehensive Teacher Induction Programs:

- $\quad$ Create Differentiated Assessments
- $\quad$ Pllow Self Supervision Opportunities
- $\quad$ Create a Needs Assessment Method
- $\quad$ Pchool/Personal Task Management Needs
- $\quad$ Teach Professional Traits
- $\quad$ Teach Effective Performance Objectives
- $\quad$ Consist with Finding a Home
- $\quad$ Reduce the "Shock" of Small Town Life
- $\quad$ Get to Know Business Leaders
- $\quad$ Get to know Civic and Community Leaders
- $\quad$ Get to Know the Culture of the School \& Community

The teacher induction process may take on other forms as well, including Beginning Teacher Assistance Programs (BTAP). Through the BTAP process, new teachers are supported by an induction team that may include school board members, superintendents, the local education association, school principals, mentors, and other central office staff. BTAP teams could also include community groups and individuals from outside the school such as business, civic, and other community leaders. The purpose of the BTAP team is to be strictly supportive for new teachers and not offered as a performance assessment. The BTAP team may create long range ongoing assistance to new teachers by assisting them with management skills, classroom planning, workload management, and community socialization. The implementation of needs assessment systems can help the BTAP team understand the specific concerns of individual beginning teachers so they may develop a plan than can celebrate and assist the arrival of new teachers (Gordon \& Maxey, 2000).

Successful teacher induction programs from around the nation implement a variety of methods to introduce new educators into their school districts: 
- $\quad$ The Flowing Wells School in Tucson, Arizona, implemented a teacher induction program for new teachers that included a bus tour of the school district so teachers can be introduced to community points of interest.

- In LaFourche Parish in Thibodaux, Louisiana, demonstration classrooms are offered to new teachers as well as monthly meetings and a graduation ceremony. The school also provides curriculum facilitators who offer ongoing support, conduct teacher observations, and offer constructive suggestions for improvement.

- Montgomery Township, New Jersey provides support to new staff members and orients them to the district's expectations and establishes professional relationships that keep teachers empowered to contribute to their school. Each year the school conducts a four-day new teacher orientation program that promotes effective classroom instruction, an understanding of the school district mission statement, and opportunities to meet with grade-level specialists. New staff are invited to become better acclimated to the workplace by school administrators, front office personnel, and community leaders (Sargent, 2003).

\section{CONCLUSIONS}

Satisfying the needs of both school administrators and first year teachers should be considered essential elements when creating a teacher induction program in rural schools. School administrators want teachers who are passionate professionals in the classroom that work hard and teach students well. First-year teachers want successful schools that offer them the best chance for long term success in their teaching careers. They want schools that are neat, tidy, safe, and offer a balanced work load, and fair class sizes, but they are reluctant to accept teaching positions in remote rural communities that offer few personal and family amenities.

Evidence supports the notion that teacher induction programs do help teachers succeed, and principals in South Dakota rural schools are generally satisfied with the performance of new teachers they have employed from Northern State University. To keep those new teachers in their schools for the long term, South Dakota principals need to create teacher induction programs that are effective in helping new teachers make the transition from lonesome outsider to valued insider. As Hoerr (2005) states, "good administrators recognize that if we want our teachers to be successful, we need to consider the range of their needs." South Dakota schools that take the time to create comprehensive, meaningful teacher induction programs can send a message for consistent professional growth as well as help transfer the culture and mission of the school and community. Research shows the benefits of teacher induction programs, including greater retention and reduced attrition rates for new teachers. Comprehensive induction programs may be the next step in supporting the needs of schools, new teachers, and local communities.

\section{AUTHOR INFORMATION}

Craig D. Kono served as classroom teacher, high school principal, and school superintendent in K-12 South Dakota schools from 1979 to 2001 . He received his Bachelor's Degree in Secondary Education in 1979 and his Master's Degree in Secondary Administration in 1988 from Northern State University in Aberdeen, South Dakota. He earned his Doctor's Degree in Educational Administration from the University of South Dakota in 2001, and is currently an Associate Professor of Educational Administration at Northern State University in Aberdeen, South Dakota. E-mail: konoc@northern.edu.

\section{REFERENCES}

1. Gordon, S.P. \& Maxey, S. (2000). How to Help Beginning Teachers Succeed. ASCD, Princeton, New Jersey 08541

2. Graziano, Claudia. (2005). School's Out. Edutopia, 1(3), 38-44

3. Hoerr, Thomas (2005). Meeting New Teachers Personal Needs. Educational Leadership 62(8) 82-84

4. Ingersoll, Richard. (2005). School's Out. Edutopia, 1(3), 38-44

5. Marczly, Bernadette. Supervision in Education: A Differentiated Approach with Legal Perspectives. Lanham, Maryland: Scarecrow Press 2001

6. Monthly Bulletin: Teacher Retirement. Pierre, SD: Associated School Boards of South Dakota, 2006

7. National Center for Educational Statistics. (2001). Teacher Follow-up Survey. Washington, DC: National Center for Education Statistics

8. Toner M. (2004). Alone on the Range. Teacher Magazine 16(1) 46-54 
NOTES 